\title{
Language, Religion, and Emplacement of Zazaki Speakers
}

\author{
Sevda Arslan ${ }^{1}$ \\ University of Notre Dame, USA
}

\begin{abstract}
Speakers of the Zazaki language present an ongoing and contested dilemma regarding their relationship and place within mainstream Kurdish identity. Academic scholarship on Zazaki speakers, and more specifically, their identity is not only scarce but often fails to provide a solid discussion on (ethnic) identification processes. The article gives an overview of scholarly research on identity in the context of ethnic membership affiliation and focuses on the case of the Zaza identity, language, religion to problematize the place and sense of belonging of its speakers. As language is the starting point, it is viewed as a key salient factor for the Zazaki identity. This article discusses the relationship between language and identity to examine the claims about whether Zazaki speakers belong to the ethnic category of "Kurd" or just "Zaza". Faith (Alevism and Sunni Islam) is also identified as a potentially competing factor shaping and defining the Zazaki identity discussion. The article concludes by proposing that we move beyond the simplistic and opposing views of Zazaki speakers as Kurds or as a distinct ethnic group. Instead, the Zazaki case provides a unique opportunity to move beyond strict categorizations of identity influenced by rigid concepts of nationalism and nationhood to a more nuanced understanding on the fluidity of identity among ethno-cultural and/or linguistic minorities and migrant groups in general.
\end{abstract}

Keywords: Zazaki speakers, Kurds, Alevis, identity, language, minorities

\section{Introduction}

Zazaki $^{2}$ speakers' ethnic identity, especially in relation to Kurdish identity, remains the subject of much controversy among the academic and the non-academic communities. The most salient component is language in defining the Zazaki identity and its emplacement within the Kurdish community. Uncontested is the fact that Zazaki language is part of the Indo-European language family further classified as a Northwestern Iranic language. It originates and is predominantly spoken by 3-6 million people in eastern Turkey whereby it is currently listed as a vulnerable language by UNESCO facing extinction. Further, about half of the Zaza speakers are reported to practice Alevism, while the other half practices Sunni Islam (Kehl-Bodrogi, 1998). Alevism, a topic of contention and debate itself due to its ambiguous relationship to Islam, is generally viewed as a syncretic religion closely influenced by Shia Islam (Arslan, 2016; Dressler, 2013; Tambar, 2014).

In this article, I tackle the question of why language plays a crucial role in Zazaki speakers' identity and emplacement in relation to and within the wider Kurdish community. Besides the language component, I also emphasize the role faith plays in the Zaza and/or Kurdish identity constructions. Hereby, I am focusing primarily on comparisons between Zazaki and Kurmanji Kurdish. Sorani, the second largest Kurdish language variant, is excluded on the basis that it is not spoken within the current borders of Turkey and because social interactions between Zaza and Soran are far less likely to occur than those between Zaza and Kurmanj. The latter share the same geographic region in eastern Turkey where Zazaki and Kurmanji speakers live in close proximity. In the diaspora, these two language groups are also more often in close contact compared to other Kurdish groups. While Zazaki is related to (other) Kurdish languages, the contention concerns the "appropriate" categorization of Zazaki language and its speakers which is highly debated among Zazaki speakers themselves and Kurds writ large. This polemic is underlined with the question of whether Zazaki is a Kurdish dialect or a distinct language. Most research on Kurdish people identifies Zazaki speakers not as a community in itself, but as part of the Kurdish nation as a given fact (Haig, 2001; Haig \& Öpengin, 2014; Hassanpour, 1992; Kaya, 2011; Sheyholislami, 2015). This categorization is not unitarily shared by linguists. In contrary, the majority of Zazaki language scholars identifies this speech variety as distinct from Kurmanji and Sorani Kurdish (Keskin, 2008; Selcan, 1998).

\footnotetext{
${ }^{1}$ Correspondence: $\mathrm{PhD}$ candidate in Anthropology. E-mail: $\underline{\text { sarslan@ } @ \text { nd.edu }}$

${ }^{2}$ In this article, I use the words Zaza and Zazaki interchangeably. More commonly, Zazaki tends to be used in reference to the language itself, while reference to the speakers includes the usage Zaza more frequently. There are other terms describing Zazaki, such as Dimilki or Kirmancki, but for legibility purposes, I have consistently used the Zaza/ki terminology.
} 
This ambiguity regarding Zazaki speakers' ethnic affiliation was reflected in my fieldwork research carried out between 2016 and 2018 among Zazaki speakers in western Turkey, Germany, and Austria. Semi-structured interviews conducted with 25 Zazaki speakers (11 women and 14 men; ranging from age 20 to 58 years old) varied in their ethnic membership identification. While some expressed a belonging to the Kurdish identity, others claimed a separate ethnic membership as Zaza/ki people, and a few favored a Turkish or Alevite label instead. The main argument for a distinct Zazaki identity follows the understanding that since Zazaki and (Kurmanji-)Kurdish are not mutually intelligible, they need to be categorized as separate languages and with that a separate ethnic group. This view had a theoretical grounding derived from language-based group identification that posits that language "constitutes the touchstone of a people or Volk" (Bauman \& Briggs, 2003, p. 169). However, I argue that the emphasis should not be on whether Zazaki is defined as a dialect of Kurdish or a language of its own, but rather what the implications and meanings of either label, language vs. dialect, signify or symbolize. Hence the power dynamics created through word choices (Phillipson, 1999) influenced and still continue to impact the Zaza and Kurdish nationalism framings, respectively.

The particular case study of Zazaki speakers contributes to scholarship engaging with the meaning and construction of ethnic identity for minority groups experiencing oppression and/or exclusion in the native and settlement countries. A discussion on Zazaki identity membership necessitates examining the links between language, religion, and place along with socio-political context over time. Like many social constructivists, the article challenges primordial and essentialist approaches that present static and inherently biological relationships between two or more factors such as "the ties religion, blood, race, language, region, and custom" constituting an ethnic identity (Hutchinson \& Smith, 1996, p. 8). A more widely acceptable approach argued by Barth (1969) is that ethnicities are interdependent and in dialogical relationships that "emphasize the fluidity and contingency of ethnic identity which is constructed in specific historical and social contexts" (Brettell, 2015, p. 164).

The next section provides a brief historical background of Zazaki speakers and literature on the Zazaki language. The theoretical foundation examines the links between language and identity for group membership criteria, namely how language can be used as a point of reference for establishing criteria of inclusiveness and exclusiveness among Zazaki speakers themselves. Here, I specifically discuss the definition dilemma regarding the language vs. dialect debate as a crucial dimension of language that establish the identity processes within and across nation-states. Moreover, ideas and everyday life experiences manifested in the European diaspora especially shaped and bolstered a separate Zazaki identity consciousness. The final section emphasizes the importance of further research as the Zazaki case's uniqueness brings a more enriched understanding about the various factors involved for national and immigrant minority communities' ways of engaging in and understanding the concept of self and group identity. It also forces a critical rethinking of how the term "Kurd" is deployed and what possible hegemonies operate.

\section{Historical Context and Population Background}

The Kurds, who primarily reside in Turkey, Iran, Iraq, Syria, and Armenia, are considered the largest stateless nation with a population number estimated to be ranging between 25 to 40 million (Gunes, 2019; Gunter, 2011). About half of the Kurdish people live in Turkey, although for the majority of the $20^{\text {th }}$ century, the official Turkish narrative denied the existence of people called Kurds or any Kurdish language. Naturally, this has starkly impeded the development of Kurdish scholarship and linguistic input. It was only when Turkish Kurds migrated to Europe that the field of Kurdish Studies began to emerge (e.g. Institute Kurde de Paris) while also bringing attention to the suppression of Kurdish people and their cultural practices in the Middle East. A few Turkish (Ergil, 2000; Kirişci \& Winrow, 1997; Yavuz, 1998), American, and European scholars (Barkey \& Fuller, 1998; Kreyenbroek, 1992; McDowall, 1992; Van Bruinessen, 1992) have contributed to the growth of the literature on the Kurds in the 1990s. In the last two decades there has been a proliferation of literature by researchers located outside of the Kurdish regions (Alogali, 2018; Calderon Berumen, 2019). This article partially seeks to contribute to this growing field. Yet, given the severity and sensitivity of the Kurdish conflicts in the Middle East, research on Kurdish issues reflect this situation, meaning that topics on nationalism, violence, and power dynamics have typically taken prevalence.

Subsequently, one understudied and taken for granted topic is the Kurdish identity itself, including who is considered to be part of the Kurdish nation along with what speech varieties are considered Kurdish languages. Language can present a viable marker for group membership affiliation. One simply categorization of speech is measured by the degree of intelligibility to decide whether two speech varieties belong into the same or separate groupings. In the case of Kurdish language varieties, there are two widely spoken Kurdish language varieties: Sorani in Iraq and Iran and Kurmanji in Turkey, Syria and parts of northern Iraq and smaller areas of western Iran near the border with Turkey. Another Kurdish language category consists of Gorani (Iran) and Zazaki (Turkey) that often are considered varieties of a second Kurdish language as they bear similarities to each other (Sheyholislami, 2015). Zazaki is the third most widely spoken language/variety after Sorani while Kurmanji is the majority spoken Kurdish variety. 
The late sociolinguist Amir Hassanpour's (1992) study on Kurdish nationalism and languages produced a map based on the location of the Kurdish languages. This map was updated by Öpengin (2013) and pictured below.

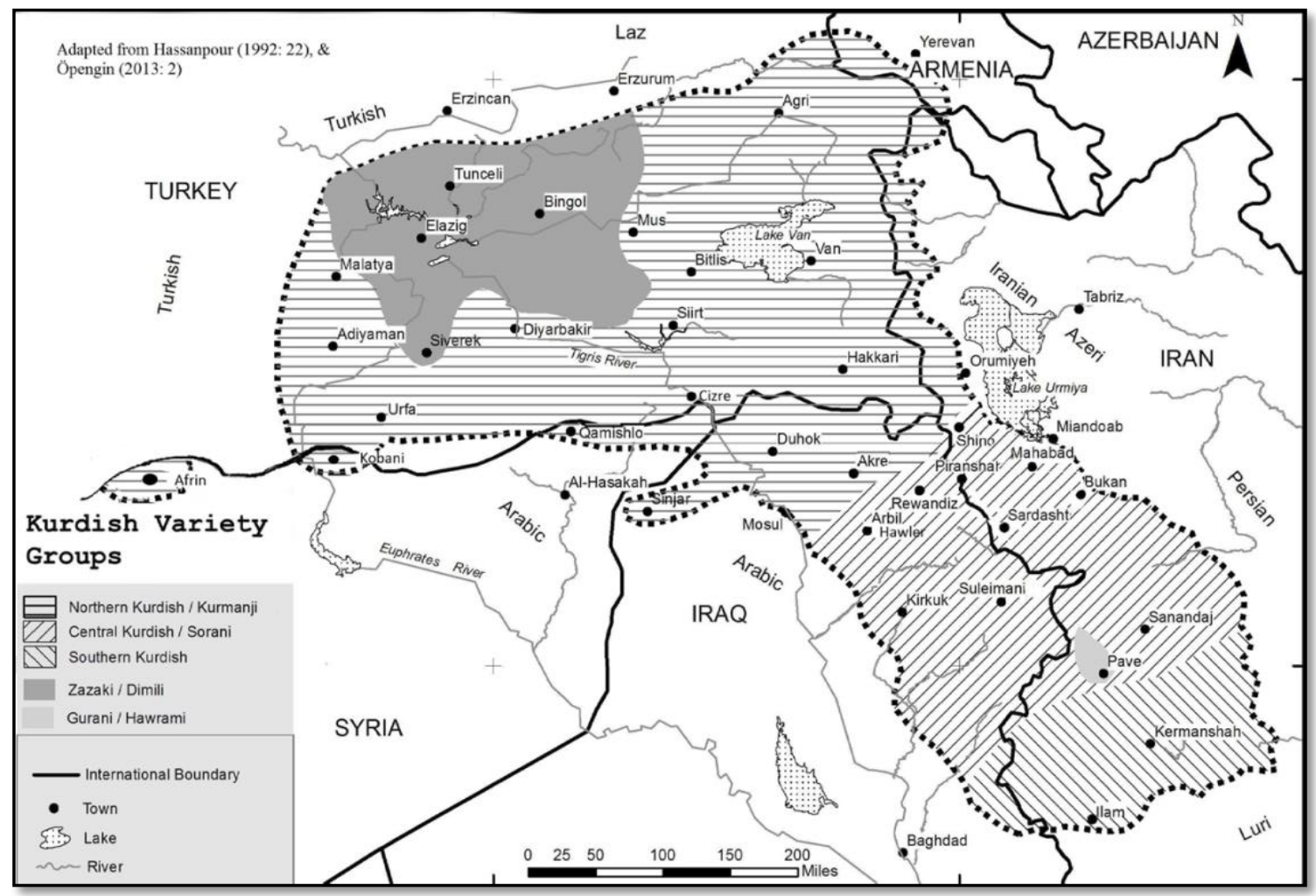

Figure 1. Map of Kurdish Variety Groups adapted from Hassanpour (1992) and Öpengin (2013), (Taucher, Vogl, \& Webinger, 2015, p. 33).

The linguistic cartography above of Kurdish variety groups puts the location of Zazaki (or Dimili which is another name for Zazaki used in the Southern Zazaki speech area) in the North Kurdistan region. Further, this region is easily distinguishable as it is marked in solid gray colors unlike the other Kurdish language regions illustrated with lines.

On an alternative map in Figure 2 below, Zazaki linguist Zilfi Selcan (1998) categorized Zazaki as a nonKurdish language. While the Zazaki speech areas partly overlap with the map in Figure 1, the main difference is that the second map only portrays Zazaki. It shows Zazaki as a distinct ethnic, linguistic, and regional population. Keskin (2008) further categorized the Zazaki speaking region comprised of three language varieties: Northern (Dersim), Central (e.g. Elazı/g/Elaziz), and Southern (e.g. Diyarbekir/Amed). The differences between these varieties are primarily of small pronunciation markers. One common speech observation is that Northern Zazaki speakers generally lack the "sh/sch" sound that is prevalent in the Southern Zazaki speech. For instance, the word "you" $\left(2^{\text {nd }}\right.$ person/plural $)$ is pronounced and written as sima in Northern Zazaki while Southern Zazaki pronounce the same word at the beginning with the letter "ş" (sounds like "sh"), i.e. şima. The "sh" sound is commonly not used in the Northern Zazaki speech variety. There are also some differences in the vocabulary of the language varieties. 


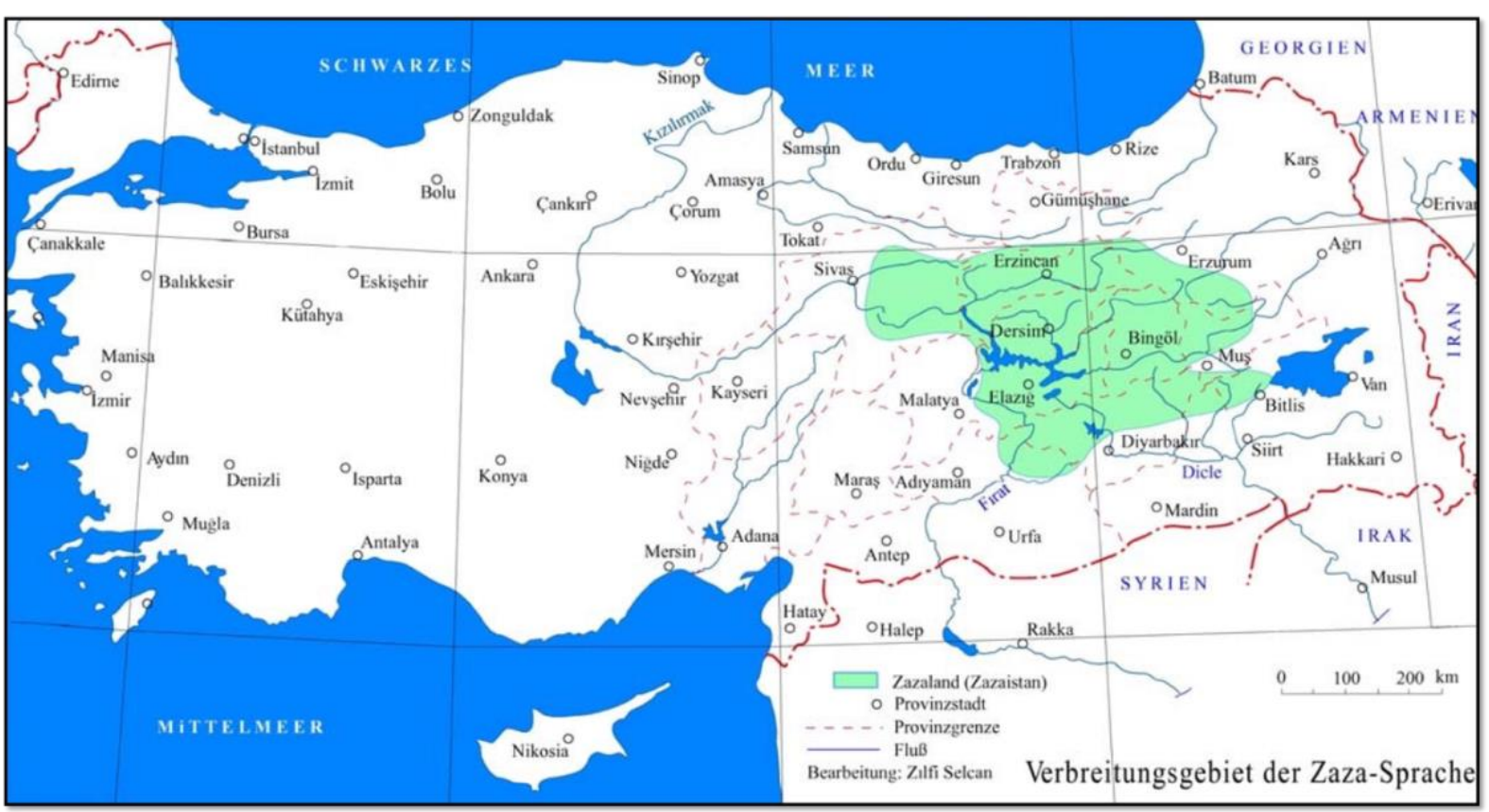

Figure 2. Map of Zazaki speaking areas in eastern Turkey (marked in green) prepared by Selcan (1998).

While Zazaki language itself has been well documented, research on Zazaki speakers remains understudied and limited to only a handful of written works. Anthropologist and Kurdish specialist Martin van Bruinessen (2015) clearly summarized these works in the following paragraph:

Most of the research as well as the polemics has concerned the Alevi Zazas, especially those of Dersim. Tankut and Sevgen, but also Asatrian and Arakelova, wrote primarily about Dersim. There is a considerable body of writing, including anthropological accounts, on the religion and cultural traditions of the Zazakîspeaking Alevis of Dersim, as well as those of Varto. On the Sunni Zazas, however, there is hardly any literature - except memoirs and studies of the Shaykh Said uprising, in which Sunni Zaza tribes were the main actors (M. Bruinessen, 2015, p. 119).

So far, there is only one published book based on anthropological research carried out by Mehmed Kaya. His approach did not engage with the Zazaki identity itself or address the saliency of Zazaki speakers' ambiguous ethnic membership. Rather, Zazaki speakers' membership among the Kurdish population is assumed and the debate surrounding this issue is circumvented, as exemplified by the choice of his words 'Zaza, Zazaki-speaking Kurds, Kurdish-speaking, Zaza Kurds and Kurds' that are used interchangeably throughout the book. Kaya (2011) also just briefly engaged with the Zazaki language controversy, neglecting to a handful number of previous linguistic works on the Zazaki language that existed:

Most specialists of Kurdish, among others Lerch (1857, 1858), claim that Zaza is a dialect of Kurdish, while a few (e.g. MacKenzie 1962; Paul 1998) assert that Zaza is perhaps a separate language and that the Zaza originally came from North Iran (p. 4).

The author only references one scholar from the 1800s as a Kurdish language specialist who categorized Zazaki as a Kurdish language while citing two more recent scholars who concluded that Zazaki was a separate language. Other leading Zaza intellectuals (e.g. Ebubekir Pamukcu) necessitated mentioning to offer a more thorough and balanced discussion of the language vs. dialect debate and a growing Zazaki identity debate. Still, Kaya's (2011) book could provide a fundamental basis as a point of reference for scholars who conduct research among Zazaki speaking diaspora; they could potentially trace some ideas and practices maintained and reconstructed in Europe to similar life experiences in the ancestral Zazaki speech regions. 


\section{Language and Identity}

The links between language and identity are undeniable and yet often blurry due to many highly charged factors of emotional, political, economic, and social nature. The intricacies concerning language issues are very powerfully illustrated through Gloria Anzaldúa's work on Borderlands in which she described the embodiment of language, meaning that language is inseparable from ethnic identity. In her own words, she stated (Anzaldúa, 1987, p. 59)

Ethnic identity is twin skin to linguistic identity - I am my language. Until I can take pride in my language, I cannot take pride in myself.

In the above quote the author suggested that language to her was inherently linked to personhood and ethnic membership, making them inseparable. Hence some people might experience an intimate relationship with their native language, in a way as if they embodied the language (Feld, Fox, Porcello, \& Samuels, 2004). This understanding can support the implementation and support for mother tongue language rights and education. Similarly, the same claims entailing essentialist language ideas have led to misuse and violence of certain people. Nationalist ideologies, for instance, contributed to our understanding of linguistic and ethnic identity where in some countries one national or official language is selected and exalted to construct a 'homogenous' nation-state (Anderson, 1991; Wimmer, 2002).

The co-naturalization of language and race/ethnicity is a prevalent phenomenon around the world (Rosa \& Flores, 2017). This link between language and identity in a primordial sense becomes a relevant and generally misused justification for constructing national identities and nationhood following the nation-state paradigm. For example, $18^{\text {th }}$ century romantic nationalism thinker Herder evoked the widespread idea that language "constitutes the touchstone of a people or Volk" - an idea which also extended into poetry and expressive culture (Bauman \& Briggs, 2003, p. 169; Tarman \& Kilinc, 2018). Language has therefore been a strong factor for studying ethnic identity claims (Reyes, 2010; Skutnabb-Kangas, 1988; Ucarlar, 2009), which in practice actually means that "ethnicity is frequently related more to the symbolism of a separate language than to its actual use by all members of a group" (De Vos, 1995, p. 23). Therefore, it is important to note that what a language symbolizes ideologically does not necessarily bear importance to everyday language practices (Belenkova, Kruse \& Wydra, 2018). In other words, an individual might express claims for a separate Zazaki identity based on the language without actually being a speaker of that language herself/himself. Cohen points out that the agency of the individual should not be reduced to a group identity. The many ways to recognize the self-consciousness of the individual includes their resistance to structures or cultural norms that crystalize the tensions between the individual and social institutions (1994, p. 181). Nevertheless, this view of language as being intrinsically linked to ethnicity can be used to understand the Zazaki language as a uniting factor for a separate Zazaki identity or equally as part of the Kurdish group claims depending on how Zazaki language is categorized. From this follows that for some Zazaki speakers, the language they speak dictates the ethnicity they belong to which in this case could primarily either be Zazaki ethnicity or the Kurdish ethnic group.

However, a critique on this ideology that language forms the basis for ethnic membership affiliation, I argue needs to consider and question 1) the authority aspect in knowledge creation, in this case concerning the language definition status and 2) a situational and holistic understanding about ethnic membership by recognizing and including factors salient for ethnic membership belonging beyond language ancestry. Other scholars also point out that belonging to an ethnic group goes beyond the mutual intelligibility of a language, such as also taking into account whether a group shares the same socio-political and/or socio-cultural background. This idea is grounded in the famous phrase that 'a language is a dialect with an army and a navy'3 to underline that language boundaries are based more on political and economic factors and not just linguistic criteria.

The influence of political power can be demonstrated through the Serbo-Croation language. The speakers of the Serbian and Croatian language find the two languages are mutually intelligible despite the fact that they each have their own sovereign state following the bitter war against each other in the early 1990s. Here, the "one language, one people" ideology did not translate into one nation-state. In contrast, some scholars argued in respect to Zazaki and Kurmanji Kurdish that both languages being mutually unintelligible is a weak argument in the grand scheme of what an identity ought to consist of. O'Driscoll (2014) pointed out that "“language' and 'dialect' need to go beyond linguistic evidence, and when social, political, and cultural factors are taken into consideration, it becomes evident that groups like Kurmanji, Zazaki, Sorani [spoken in Iraq], etc., are all Kurdish and thus speak the Kurdish language" (O'Driscoll, 2014, p. 273). Language alone may not necessarily influence the creation or rise of a specific identity.

However, the differences between the Zaza and the Kurmanj have become much more prominent in the diaspora than in the ancestral land. As diaspora groups are known for constructing both the past and the future of the

\footnotetext{
${ }^{3}$ The sociolinguist Max Weinreich (1894-1969) is usually associated with this phrase.
} 
"homeland" (Axel, 2002; O'Shea, 2004), differences then may arise in what constitutes such a notion or idea of "Kurdistan". For instance, according to Kehl-Bodrogi (1998), the diaspora community actually bolstered the Zazaki identification process which resulted in the polemic of Zazaki identity and the politicization of the issue. Kehl-Bodrogi (1998) argued that an awareness of Zazaki being a separate group did not just result due to the apparent linguistic differences between Zazaki and Kurmanji. Rather the Turkey-originated Kurdish movement in Europe promoted a Kurdish identity based on the Kurmanji language which translated as being Kurdish meant speaking Kurmanji, hence was not encompassing of Zazaki speakers (Kehl-Bodrogi, 1998, p. 122). Moreover, she pointed out that since local languages were banned in Turkey, the linguistic differences were not relevant and did not become as evident as they did in Europe. As these linguistic differences, along with the ideologies became more salient some Zazaki speakers felt discriminated against and accused Kurmanji speaker to engage assimilative practices as done by the Turkish state (ibid).

Arakelova (1999) too, wrote that the Zaza national identity was always "under the shadow of the Kurdish ethnic and national prevalence" and had been "totally suppressed by the Kurd's political strivings manifested in numerous movements" (Arakelova, 1999, p. 397). Regardless of whether a Zaza identified as Kurd or not, their distinct Zaza identity and voice would be submerged within the larger frame of the political struggle that was Kurmanji dominated. For some Zaza in Europe, such a trajectory actually made them distance themselves further from both the Kurdish struggle and the Kurdish identity as they as a smaller minority within a larger minority could not break the Kurmanj hegemony, and certainly not the Turkish hegemony. As such, for some Zaza the "Kurd" began to constitute an "Other" rather than "Self". Then, the struggle for Zaza cultural, linguistic and political rights called for a separation from the wider Kurdish struggle. Hence the framing of a Kurdish identity itself, such as emphasizing certain languages over others, might be regarded as a potential trigger for the construction of a separate Zazaki identity among diaspora communities.

Another argument for the multiple ways that language and ethnic membership can be formed or not is illustrated with the case of Turkish replacing Kurdish. A study with 90 Kurds living in London revealed that "one way in which [Kurdish] brokers engaged in de-Turkification was through the assertion of 'being Kurdish, but speaking Turkish"' (Demir, 2017, p. 281). Many of the participants expressed that simply because they could not speak Kurdish did not mean that they were not Kurds. This example shows that even in the case of minority groups, stateless nations, one language might be replaced with another without necessarily interpreting this as a change of their ethnic/national affiliation.

My fieldwork observations at religious and cultural sites in Vienna and Berlin attended by Zazaki and Kurmanji speakers showed that in everyday practice, Zazaki and Kurmanji languages were hardly present. In Germany and Austria, Turkish language practices continue to dominate, if not exclusively used. Even at primarily Zazaki or Kurdish events (e.g. musical concerts or cultural festivals), Turkish remained the lingua franca during many of the events. Even written communication is dominated by the Turkish language where the group members are overwhelmingly of Zazaki or Kurmanji language background, as it can be observed on social media sites such as Facebook or on flyers and information documents (sometimes German translations existed). Conversation in Zazaki only occurred if individuals (usually middle-aged and older) engaged in dialogue were all fluent speakers within small groups of two or three people. These conversations too, entailed much code-switching between Zazaki and Turkish, including occasional German words. The question, then, arises as to how to best capture the existing apparent contradictions between ideological viewpoints and everyday linguistic practices that shape and dictate group membership identification claims.

\section{The Language-Dialect Debate}

As mentioned earlier, for some, the Zazaki question boils down to whether it is a dialect/variety or language, making the linguistic classification of Zazaki and consequently Kurdish language(s) one salient point of contention. While the term "dialect" is still used in academic works, linguists and anthropologists overwhelmingly agree that the term dialect inaccurately establishes hierarchies between languages, and it would be more accurate to speak of language varieties or just languages. Irrelevant of the terminology dialect or variety, I have summarized the debates concerning the linguistic classification of Zazaki. The chart in Figure 3 below demonstrates visually the arguments concerning the relationships between language and ethnicity. 


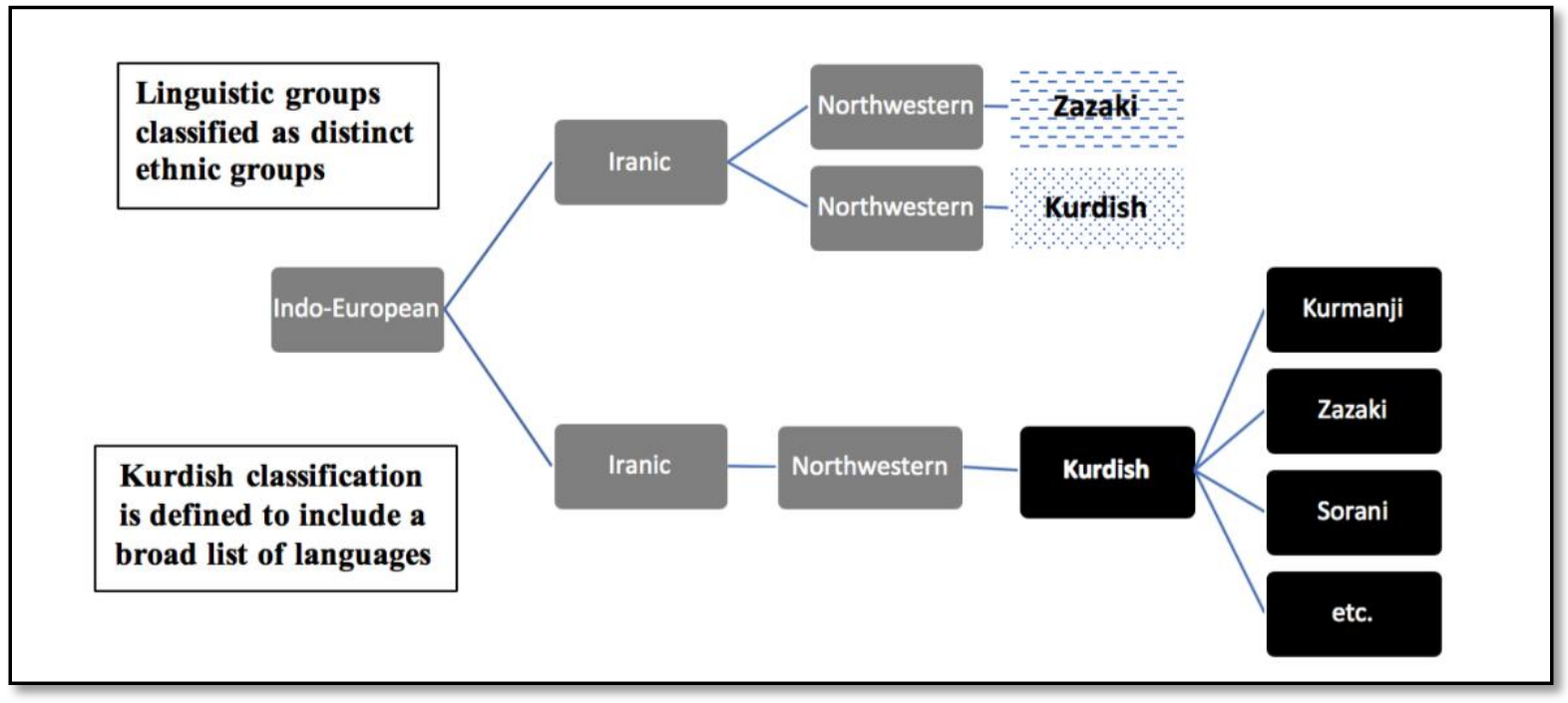

Figure 3. Zazaki - Kurdish Language Classification Debates

As pointed out elsewhere, the majority of linguists support the definition that Zazaki is different from Kurmanji and define it as a distinct language (Gippert, 1996; Keskin, 2008; Paul, 1998; Selcan, 1998). However, there is also the counterview that argues that a linguistic definition can be followed by the speakers' self-ethnic identification. On a similar line of argument this understanding also requires to be more critical of language classifications in first place, including asking the question to what extent historical socio-political developments are taken into account when comparing two speech communities. In a special issue on Kurdish languages, this idea was formulated by another set of linguists in the following way about the case of Zazaki language and speakers:

It is perfectly possible to accept both the conclusions of the historical linguists (Zazaki is historically not closely related to Kurmanji), and the conclusions of many native speakers (Zazaki speakers are Kurds, and their language belongs to a larger-order entity "Kurdish"). There is not necessarily any contradiction here (Haig \& Opengin, 2014, p. 111).

Haig and Opengin (2014) seem to suggest that the contours between Kurdish language and Kurdish identity are quite malleable. Indeed, Çetkin (2016) points out in her interviews with young Zazaki speakers between the ages of 20 and 30 that mainly linguistic claims were used in favor of a Zazaki or Kurdish identity. She notes the following (Çetkin, 2016, pp. 49-50):

The ones who think that Zazaki speaking people are Kurdish defend their ideas by pointing out the similarities between the two languages, whereas the ones who think that they are from a separate origin defend their views by highlighting the differences between the two languages.

Çetkin's (2016) interviewees are all living in Turkey where because of the greater number of Zazaki and also (Kurmanji)Kurdish speakers, we can expect more intense contact between these groups, for example at university settings (given the age of her interviewees). However, I had similar results in my interviews with similar aged Zazaki speakers in the European diaspora, Germany and Austria. In the diaspora, Zazaki speakers based their views for a distinct Zaza/ki ethnicity on linguistic grounds. Here, the main emphasis was placed on the unintelligibility of these two languages. At the same time, some Zazaki speakers expressed belonging to Kurdish ethnicity despite their view of Zazaki being considered a language and not just a Kurdish variety.

Another prevalent piece of information that some Zazaki speakers in Turkey and the diaspora I interacted with felt compelled to share was that UNESCO had categorized Zazaki as a 'dying' language. In the updated 2010 edition on the Atlas of the World's Languages in Danger the UNESCO report, wrote the following about the vitality of Zazaki and Kurdish in Turkey (Moseley, 2010, pp. 40-41): 
One North-Western Iranian language, Zazaki, is spoken exclusively in Turkey, and despite having a high number of speakers, it must be regarded as vulnerable at the minimum. Of the North-Western Iranian languages, two more are represented in the region: Kurmanji (Northern Kurdish), spoken mainly in Turkey but also in the neighbouring countries in the Caucasus and the Middle East, cannot be regarded as endangered.

It is important to note that the UNESCO's choice of words might indirectly support claims to separate Zazaki ethnic identity from the Kurdish one. It not only explicitly defines Zazaki as a language, but there is also no mention as to how it might relate to the Kurdish language(s) except that both are classified as Northwestern Iranian languages. This growing awareness about the precarious state of Zazaki language tends to be frequently emphasized by Zazaki activists in Turkey and Europe alike with this knowledge having intensified their emotional sentiments towards their mother tongue language. Accordingly, in the last few years, on February 21 on the International Mother Language Day, Zazaki activists and sympathizers alike take on the streets or organize events to bring attention to the vulnerable status of Zazaki. Even a few specialized online news channels (e.g. bianet ${ }^{4}$ and $t 24^{5}$ ) brought up this concern to the public's attention.

Zazaki being categorized "as vulnerable at the minimum" means that the language is on the path to extinction unlike (Kurmanji-)Kurdish which creates greater inequality between the linguistic survival potential of Kurmanji and Zazaki. Although it is necessary to note that Kurmanji Kurdish has a significantly higher number of speakers and a longer tradition as a literary language. Still, some Zazaki language advocates resent the lack of responsibility coming from Kurmanji speakers. Some of these concerns regarding the place Zazaki holds within a Kurdish identity were underlined by one interviewee. The meeting took place with one of my male participants over coffee at one of his favorite places in western Germany which happened to be a Kurdish café. Although we overwhelmingly communicated in German, he was a fluent Zazaki speaker, including Turkish and some others. As the conversation deepened on language politics and the links between Zazaki and Kurdish, he proclaimed the following (personal interview, Dec. 2016):

Die Kurden können den Zazas gar nicht weiterhelfen [...]. Wessen Verdienst ist es, dass Zaza gerade da ist?

The Kurds cannot help the Zazas, at all [...]. Who can take credit for Zazaki currently existing?

In this statement above, the individual pointed out that scholarship to document Zazaki language and culture and general efforts to maintain the language in everyday life has not been supported by Kurmanji speakers who merely classify Zazaki as a Kurdish language. While the Kurmanj domination is undeniable, it is also necessary to reemphasize that the Kurds at large have been living in the shadows of the Turkish majority in Turkey. Their exclusion of the Zaza identity does not bear the same legal, political and economic ramification as that of the exclusion or discrimination by the Turkish nation-state or government. There are diverse actors at play at multiple levels using different methods, power, and resources that affect the perception of Other and Self among the Zaza speakers. A lack of political power on a governmental level, nevertheless, does not prevent unequal standing between the variety of Kurdish language speakers. For instance, while Kurdish Studies is still a growing field, and most recognize the diversity of the people encompassing Kurdistan, this diversity often seems to be diminished due to the lack of scholarship dealing with Zazaki speakers.

Nevertheless, despite the marginalized status of Kurdish people, a specific hegemonic practice can be observed in the popularity of language course choices. As a language instructor for German and Zazaki, my research participants explained that while Zazaki speakers acquiring Kurmanji-Kurdish is not uncommon, the reverse is very rare for a Kurmanji speaker to show interest in a Zazaki language course as shown in the statement below:

Zazaki würde aussterben, wenn es ein Kurdistan gäbe. Es gibt nur wenige Kurmanji, die das Zazaki lernen.

Zazaki would go extinct if there was a Kurdistan. There are only very few Kurmanjispeakers who learn Zazaki.

\footnotetext{
${ }^{4}$ Bianet, 2009. "UNESCO: Türkiye'de 15 Dil Tehlikede [15 Languages are endangered in Turkey] https://bianet.org/bianet/bilim/112702-unesco-turkiye-de-15-dil-tehlikede

${ }_{5}$ t24, 2010. "'Zazaca apayri bir dil ama.."”[Zazaki is a distinct language, but..] https://t24.com.tr/haber/zazaca-apayri-bir-dil-ama,108896
} 
The above statements reveal two crucial points. First, on the surface the conversation about Zazaki speakers seems to be merely concerning their ethnic membership as either part of the Kurdish identity or a separate one. Yet, going beyond a simple classification, this debate revealed more about the relationship dynamics among Zazaki and Kurmanji speakers. Hence, the definition of Zazaki language presented ideas about the speakers and more specifically how they relate to others (i.e. Kurmanji speakers) in close proximity. This understanding was already expressed by Raymond William's language definition that "a definition of language is always, implicitly or explicitly, a definition of human beings in the world" (Williams, 1977, p. 21). Therefore, the point to focus on is no longer about whether Zazaki speakers belong to the Kurdish nation or not, but instead we need to identify and understand what meanings either classification actually carries with it. Secondly, the question to ask would be if the language component was disregarded, would it still matter how people of Zazaki language ancestry were categorized into an ethnic group? Since both Zazaki and Kurmanji are threatened and weakened, and to a large extent replaced by Turkish or German, the Zazaki case paves the way for inquiries into a more refined perspective on the links between language and identity when the ethnic identity is primarily shaped by the precarious state of a language.

\section{Saliency of Faith: Alevi Zaza and Sunni Zaza?}

Besides language issues, faith plays an important role in the Zazaki identity debate. Some research on Alevi Zazaki speakers in the diaspora revealed that Alevi and Sunni Zazaki speakers should be viewed as separate cultural groups, rather than a single group based on linguistic boundaries (Can, 2013; Kaya \& 2013; Tasci, 2008). These distinctions can often be predicated on the "strength" of affinity for different aspects of Zazaki culture, hereby making faith the dominant and inclusionary or exclusionary criteria for group membership (Can, 2013; Tasci, 2008). The weight of faith continues to bear significance throughout the world. However, in the case of Turkey, this emphasis can also be traced back to the Ottoman Empire which practiced group affiliation through religion rather than ethnicity as demonstrated by the 'millet' (community) system which categorized people of similar faith together and it was the main identifier for group membership such as the Greek Orthodox millet, Armenian millet, Jewish millet and Muslim millet (Kaya, 2015; Ucarlar, 2009). The Alevis were considered part of the Muslim millet during the Ottoman era. Still today, religion continues to be a salient factor for group inclusivity and exclusivity in Turkey (Park, 2012; Tambar, 2014; Tarman, 2010; Zürcher, 2004)

The faith-based divide between Alevi and Sunni Zazas can also be physically observed, meaning that geographically, Sunni and Alevi rural regions in eastern Turkey have historically been quite isolated from one another. Despite one common language, there has been little contact among Alevi and Sunni Zazaki speakers in the ancestral villages for a number of reasons such as lack of transportation methods, harsh geographical terrain, and poor roads that characterizes much of the region until this day. For many Zazaki speakers, the awareness of the other occurred as a result of internal and external migration. Even today in the diaspora communities, it is not too uncommon to come across Zazaki speakers who express unawareness of the existence of Zazaki speakers from a different faith (Interview 2017/07/29 in Izmir, Turkey and Interview 2018/05/29 in Vienna, Austria). The lack of contact and different religious affiliations influenced some scholars to suggest the need to consider Zazaki speakers of Sunni and Alevi background as two separate social groups (M. M. v. Bruinessen, 1997; Kehl-Bodrogi, 1998).

\section{Concluding Remarks}

On the surface, the mainstream debate on Zazaki speakers' identity is overwhelmingly concerned with the question of how they relate to the Kurdish people and whether they are part of the Kurdish community or a distinct group. This is a problematic dichotomy as it essentializes or categorizes Zazaki speakers' identity first and foremost on the language criterium. Due to very limited and scarce Zazaki studies research even the Zazaki language categorization remains a very contested area. The vulnerable state of Zazaki declared as a disappearing language by UNESCO points out to the saliency and fragile state of the language. Given the decreasing number of Zazaki speakers some questions to consider would be how actual language ability impacts identity: Are you still considered Zazaki or Kurdish if you do not speak the language? Why does it matter to frame your ethnic identity component based on your ancestral language, even in cases where one barely practices it or has never learned it, at all? Authors such as Gloria Anzaldúa wrote about the inseparable link between someone's (ethnic) identity and the language one spoke. How is this linguistic embodiment achieved through everyday life practices and how is this form of embodiment passed on to (younger) generations who were not taught their ancestral language(s)?

Yet, the Zazaki identity controversy demonstrates that group identity does not always follow predetermined script. In other words, while Zazaki speakers may ground their identity in the interplay of language, socio-political background, and/or faith, the saliency of these factors may differ for each member. There is also a delicate line to be drawn between avoiding essentialization of minority groups on the one hand and dismissing their personal experiences and perceptions on the other hand. 
This article identified the need for further research on the identity fluidity, particularly among minority, migrant and stateless groups, in relation to linguistic affiliation, views, and practices, including the power dynamics involved that influence and shape the saliency of various factors involved for ethnic identity affiliation. In terms of future research, the Zazaki identity debate requires further research on the Zazaki identity through everyday life observations, especially to understand these processes involved in minority identification as a result of migration to big cities in Turkey as well in Europe. Ethnographic studies are be best positioned to address identity dilemmas since they entail long-term commitment to communities examined and are able to decipher between ideas and practices when it comes to the creation, fluidity, and performativity of identification processes.

\section{Acknowledgements}

Thanks to Drs. Arin Savran and Stan Thangaraj and the anonymous reviewers for thoughtful comments and suggestions on this article.

\section{References}

Alogali, A. (2018). World Englishes: Changing the Paradigm of Linguistic Diversity in Global Academia. Research in Social Sciences and Technology, 3(1), 54-73. Retrieved from http://ressat.org/index.php/ressat/article/view/342

Anderson, B. R. O. (1991). Imagined Communities: Reflections on the Origin and Spread of Nationalism (Rev. and extended ed.). London; New York: Verso.

Anzaldúa, G. (1987). Borderlands: the new mestiza = La frontera (1st ed.. ed.). San Francisco: Spinsters/Aunt Lute.

Arakelova, V. (1999). The Zaza People as a New Ethno-Political Factor in the Region. Iran \& the Caucasus, 3/4, $397-$ 408.

Arslan, Z. (2016). Eine religiöse Ethnie mit Multi-Identitäten - Die europäisch-anatolischen Alevit_Innen auf dem Weg zur Institutionalisierung ihres Glaubenssystems. Wien: Lit Verlag.

Axel, B. K. (2002). The diasporic imaginary. Public Culture, 14(2), 411. doi:10.1215/08992363-14-2-411

Barkey, H. J., \& Fuller, G. E. (1998). Turkey's Kurdish question. Lanham, MD: Rowman and Littlefield.

Barth, F. (1969). Ethnic groups and boundaries: the social organization of culture difference. London: Allen \& Unwin.

Bauman, R., \& Briggs, C. L. (2003). Language, Poetry, and Volk in Eighteenth-Century Germany: Johann Gottfried Herder's Construction of Tradition. In Voices of modernity: language ideologies and the politics of inequality. Cambridge, UK; New York: Cambridge University Press.

Belenkova, N , Kruse, I, Wydra, D . (2018). Language mediators' support for refugees at border crossing points: enhancing societal tools for sustainable communication in multicultural communities of Austria, Germany and Russia. Journal of Social Studies Education Research, 9 (4), 214-230. Retrieved from http://dergipark.org.tr/jsser/issue/43626/534258

Brettell, C. (2015). Theorizing Migration in Anthropology - The Cultural, Social, and Phenomenological Dimensions of Movement. In C. Brettell \& J. F. Hollified (Eds.), Migration Theory: Talking across Disciplines (pp. 148197). New York: Routledge.

Bruinessen, M. (2015). Review of book The Zaza Kurds of Turkey: A Middle Eastern Minority in a Globalised Society. Kurdish Studies, 3(1), 118-121. doi:10.33182/ks.v3i1.395

Bruinessen, M. (1997). 'Aslini inkar eden haramzadedir': The debate on the ethnic identity of the Kurdish Alevis. 76, 1.

Calderon Berumen, F. (2019). Resisting Assimilation to the Melting Pot:. Journal of Culture and Values in Education, 2(1), 81-95. Retrieved from http://cultureandvalues.org/index.php/JCV/article/view/25

Can, H. (2013). Alevi-Zaza Belongings Beyond Borders: Insider/Outsider Attributions and Identity Empowerment Strategies in Transnational and Multigenerational Family Spaces between Turkey and Diaspora. German Politics and Society, 31(2), 79-92. doi:10.3167/gps.2013.310207

Cohen, A. P. (1994). Self consciousness an alternative anthropology of identity. London; New York: Routledge.

Çetkin, S. r. (2016). Search of ZaZaki Speaking individualS for identity. Bingöl Üniversitesi Yaşayan Diller Enstitüsü Dergisi, 2(4), 46-58.

De Vos, G. (1995). Ethnic Pluralism: Conflict and Accommodation: The Role of Ethnicity in Social History. In G. De Vos (Ed.), Ethnic Identity (pp. 15-47).

Demir, I. (2017). Shedding an Ethnic Identity in Diaspora: De-Turkification and the Transnational Discursive Struggles of the Kurdish Diaspora. Critical Discourse Studies, 14(3), 276-291. doi:10.1080/17405904.2017.1284686

Dressler, M. (2013). Writing religion: the making of Turkish Alevi Islam. New York: Oxford University Press.

Ergil, D. (2000). The Kurdish question in Turkey. Journal of Democracy, 11(3), 122-135. 
Feld, S., Fox, A. A., Porcello, T., \& Samuels, D. (2004). Vocal Anthropology: From the Music of Language to the Language of Song. In A. Duranti (Ed.), A Companion for Linguistic Anthropology (pp. 321-345).

Gippert, J. (1996). Pêseroka Zon u Kulturê Ma: Dımıli-Kırmanc-Zaza. Ware, 10, 148-154.

Gunes, C. (2019). The Kurds in a new Middle East: the changing geopolitics of a regional conflict: Cham, Switzerland: Palgrave Macmillan.

Gunter, M. M. (2011). Historical dictionary of the Kurds (2nd ed.. ed.): Lanham, Md.: Scarecrow Press.

Haig, G. (2001). Grammatik der Zaza-Sprache. Nord-Dialekt (Dersim-Dialekt).(Selcan, Zulfu)(Review). In (Vol. 39, pp. 181).

Haig, G., \& Öpengin, E. (2014). Introduction to Special Issue - Kurdish: A critical research overview. Kurdish Studies, $2(2), 99-122$

Hassanpour, A. (1992). Nationalism and language in Kurdistan, 1918-1985.: Mellen Research University Place.

Hutchinson, J., \& Smith, A. D. (Eds.). (1996). Ethnicity. Oxford: Oxford University Press.

Kaya, I., \& Aydin, H. (2013). The question of mother tongue education in Turkey: Challenges, experiences, and model recommendations for bilingual education. İstanbul: UKAM Press.

Kaya, M. S. (2011). The Zaza Kurds of Turkey a Middle Eastern minority in a globalised society. London: I.B. Tauris.

Kaya, Y. (2015). The Opinions of Primary School, Turkish Language and Social Science Teachers Education in the Mother Tongue (Kurdish). Journal of Ethnic and Cultural Studies, 2(2), 33-46.

Kehl-Bodrogi, K. (1998). „Wir sind ein Volk!“ Identitätspolitiken unter den Zaza (Türkei) in der europäischen Diaspora. Sociologus, 48(2), 111-135.

Keskin, M. (2008). Zur dialektalen Gliederung des Zazaki.

Kirişci, K., \& Winrow, G. M. (1997). The Kurdish Question and Turkey: An example of a trans-state ethnic conflict. London: Frank Cass.

Kreyenbroek, P. G. (1992). On the Kurdish language. In P. G. Kreyenbroek \& S. Sperl (Eds.), The Kurds: A contemporary overview (pp. 68-83). London: Routledge.

McDowall, D. (1992). The Kurdish question: A historical review. In P. G. Kreyenbroek \& S. Sperl (Eds.), The Kurds: A contemporary overview (pp. 10-32). London: Routledge.

Moseley, C. (Ed.) (2010). Atlas of the World's Languages in Danger (3rd ed.). France: UNESCO.

O'Driscoll, D. (2014). Is Kurdish Endangered in Turkey? A Comparison between the Politics of Linguicide in Ireland and Turkey. Studies in Ethnicity and Nationalism, 14(2), 270-288. doi:10.1111/sena.12093

O'Shea, M. T. (2004). Trapped Between the Map and Reality: Geography and Perceptions of Kurdistan. New York \& London: Routledge.

Park, B. (2012). Modern Turkey - People, state and foreign policy in a globalized world. Abingdon: Routledge.

Paul, L. (1998). The position of Zazaki among west iranian languages. Old and Middle Iranian Studies Part I, 163-176.

Phillipson, R. (1999). Political Science. In J. Fishman (Ed.), Handbook of Language and Ethnic Identity (pp. 94-108). New York; Oxford: Oxford University Press.

Reyes, A. (2010). Language and ethnicity. In N. Hornberger \& S. L. McKay (Eds.), Sociolinguistics and language education (pp. 398-426). Clevedon: Multilingual Matters.

Rosa, J., \& Flores, N. (2017). Unsettling race and language: Toward a raciolinguistic perspective. 46(5), 621-647. doi: $10.1017 /$ S0047404517000562

Selcan, Z. (1998). Grammatik der Zaza-Sprache - Nord Dialekt (Dersim Dialekt). Berlin: Wissenschaft \& Technik Verlag.

Sheyholislami, J. (2015). Language Varieties of the Kurds. In W. Taucher, M. Vogl, \& P. Webinger (Eds.), The Kurds: History -Religion - Language - Politics (pp. 30-51). Vienna, Austria: Austrian Federal Ministry of the Interior.

Skutnabb-Kangas, T. (1988). Multilingualism and the education of minority children. In T. Skutnabb-Kangas \& J. Cummins (Eds.), Minority education. Avon and Philadelphia: Multilingual Matters.

Tambar, K. (2014). The reckoning of pluralism: political belonging and the demands of history in Turkey. Stanford, California: Stanford University Press.

Tarman, B. (2010). Socio-Cultural Transformation: Western-oriented Modernization of Turkey, VDM Publishing House. (ISBN: 978-3-639-19096-0)

Tarman, B. \& Kilinç, E. (2018). Poetry in the Social Studies Textbooks in Turkey. Journal of Culture and Values in Education, 1(1), 50-62. Retrieved from http://cultureandvalues.org/index.php/JCV/article/view/4

Tasci, H. (2008). Die zweite Generation der AlevitInnen zwischen religiösen Auflösungstendenzen und sprachlichen Differenzierungsprozessen. In M. Sökefeld (Ed.), Aleviten in Deutschland: Identitätsprozesse einer Religionsgemeinschaft in der Diaspora (pp. 133-154). Bielefeld: Transcript Verlag.

Taucher, W., Vogl, M., \& Webinger, P. (2015). The Kurds: History -Religion - Language - Politics. Vienna, Austria: Austrian Federal Ministry of the Interior. 
Arslan, S.

Ucarlar, N. (2009). Between Majority Power and Minority Resistance: Kurdish Linguistic Rights in Turkey. In (Vol. 157).

Van Bruinessen, M. (1992). Kurdish society, ethnicity, nationalism and refugee problems. In P. G. Kreyenbroek \& S. Sperl (Eds.), The Kurds: A contemporary overview (pp. 33-67). London: Routledge.

Williams, R. (1977). Marxism and literature. Oxford: Oxford University Press.

Wimmer, A. (2002). Nationalist exclusion and ethnic conflict: Shadows of modernity. Cambridge: Cambridge University Press.

Yavuz, M. H. (1998). A preamble to the Kurdish question: The politics of Kurdish identity. Journal of Muslim Minority Affairs, 18(1), 9-18.

Zürcher, E. J. (2004). Turkey - A modern history (3rd ed.). London: I.B. Tauris. 